\title{
LOCALIZATION PRACTICES IN TRADING CARD GAMES. MAGIC: THE GATHERING FROM ENGLISH INTO PORTUGUESE*
}

\section{PRÁTICAS DE LOCALIZAÇÃO EM JOGOS DE ESTAMPAS ILUSTRADAS. MAGIC: THE GATHERING DO INGLÊS PARA O PORTUGUÊS}

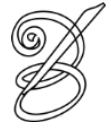 \\ Meggie Rosar FORNAZARI \\ Pesquisadora autônoma \\ Florianópolis, Santa Catarina, Brasil \\ orcid.org/0000-0001-7062-2620 \\ meggierf@gmail.com
}

\begin{abstract}
The localization of a long-lasting and often updated Trading Card Game (TCG) such as Magic: The Gathering (USA, 2003-present) requires specific and detailed translation for consistency, while following certain policies. A parallel, bilingual corpus was created to observe technical constraints and localization policies pertaining to its translation into Brazilian Portuguese. The text of 249 cards in each language was extracted, aligned, and analyzed using Wordsmith 3.0 and Notepad++, with theoretical support of a translation description model (Lambert and Van Gorp) adapted for the genre. Macro and micro analyses both resulted in a translation product that is linguistically adequate to the target system, but not acceptable in the target cultural system. Also, some sections of the product require less rigidity in relation to the game rules and could benefit from transcreation. Keywords: Translation Practices. Localization. Trading Card Games. Magic The Gathering.
\end{abstract}

Resumo: A localização de um Jogo de Estampas Ilustradas de longa duração e atualização frequente como Magic: The Gathering (EUA, 2003-atual) requer tradução específica e detalhada em relação à consistência lexical, ao mesmo tempo que certas políticas devem ser seguidas. Este estudo apresenta um corpus paralelo e bilíngue criado a fim de observar restrições técnicas e políticas de localização que possam ser pertinentes à tradução de tal material do inglês ao português do Brasil. Para tal fim, o texto de 249 cards em cada língua foi extraído, alinhado e analisado utilizando os programas Wordsmith 3.0 e Notepad++, adotando-se como aporte teórico o modelo descritivo de traduções criado por Lambert e Van Gorp adaptado para o gênero. Tanto a macro quanto a micro análise resultaram na observação de um produto tradutório linguisticamente adequado ao sistema-alvo do português, mas que não é aceitável em seu sistema cultural. Além disso, certas seções do produto que requerem menos rigidez em relação às regras do jogo poderiam ganhar em qualidade com o uso da transcriação.

Palavras-chave: Práticas Tradutórias. Localização. Jogos de Estampas Ilustradas. Magic The Gathering. 


\section{Introduction}

$\mathrm{H}$ ow are card games localized? Unfortunately, due to Non-Disclosure Agreements, most of the localization teams are unable to provide data for academic research; therefore, only the published product can be analyzed to derive their practices. According to Lambert and Van Gorp, a translated product can be seen as adequate (following the target language rules and creating understandable text in that language) and/or acceptable (going beyond language-bound obligations to create a product that is also culturally acceptable as something created specifically for the target audience). This pendulum in decision-making during translation is added to a certain amount of constraints that will limit the final translation product in some ways. In games, localization is the linguistic adaptation of a given product, alike translation but with cultural and technical aspects added (Palumbo). Games are released simultaneously worldwide, and consistency is expected in the finished product, with the same translation choices used on all instances where contextually required. Trading Card Games (TCGs) have limited text and translation must reflect game rules followed by players. Policies can be determined by Research and Development or other departments (Creative, Marketing,

146 Legal) and must be followed under all circumstances. Under so many constraints from this and perhaps more areas of development, what product can a localization team yield?

This paper reports on an investigation of translation practices in a previously translated and released TCG using a corpus with a view to deriving its translation policies. Magic: The Gathering (MTG) is the first TCG ever produced; players collect cards for displaying, trading, selling, or auctioning - and to duel with 2 or more players, building decks under several deckbuilding rules and game formats. Players act as planeswalkers - beings that summon Creatures, use Artifacts, and cast Sorceries, Enchantments, or Instant spells or enlist Planeswalker allies (see Figure 1). Playing cards of these types requires paying a mana cost (the energy which fuels magic) generated by Land cards of five different colors.

Consumers need "product information, software, user manuals, games, educational materials" (Hartley, 106) in their native language, which sparked needs for localization. MTG releases four card sets (approximately 1,000 cards) per year, simultaneously and fully localized in all aspects: "text, voiceover, manual, and packaging" (Chandler and Deming, 10). The game is currently released with localizations into ten languages (French, German, Italian, Spanish, Russian, Simplified and Traditional Chinese, Japanese, Korean, and Brazilian Portuguese). MTG voiceover is usually subtitled. 
Figure 1 - Creature, Artifact, Sorcery, Instant, Planeswalker, and Enchantment card samples
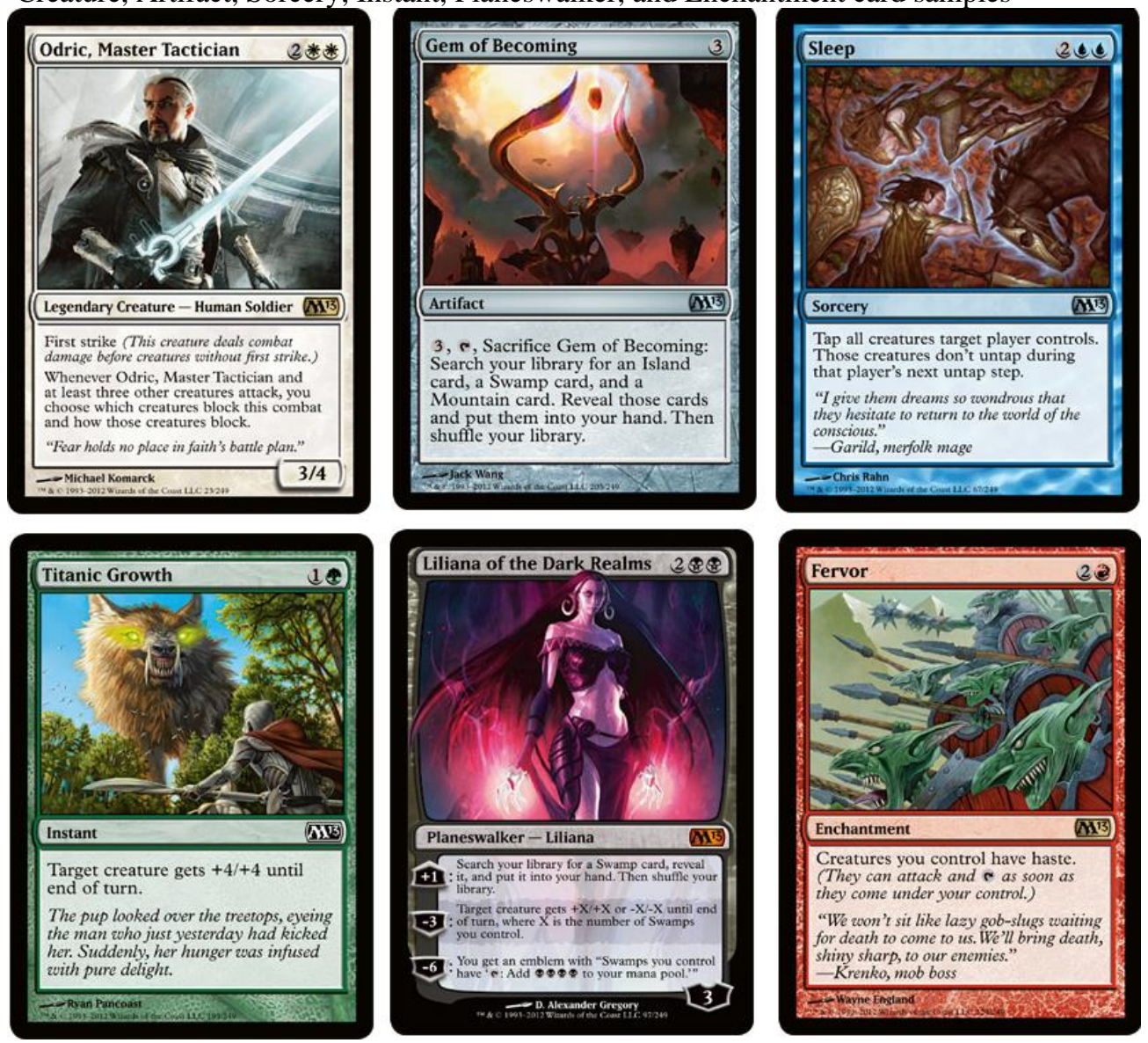

Source: Wizards of the Coast (Gatherer) - $75 \%$ of original size.

English is the game's development language (Chandler and Deming) and source language to its localizations. Only Brazilian Portuguese specifies a locale in its localization list, although it is sold and used in all Portuguese-speaking markets. This implies that a majority of Portuguesespeaking players is Brazilian.

Figure 2: Creature-type cards with examples of static, triggered, and activated abilities, respectively
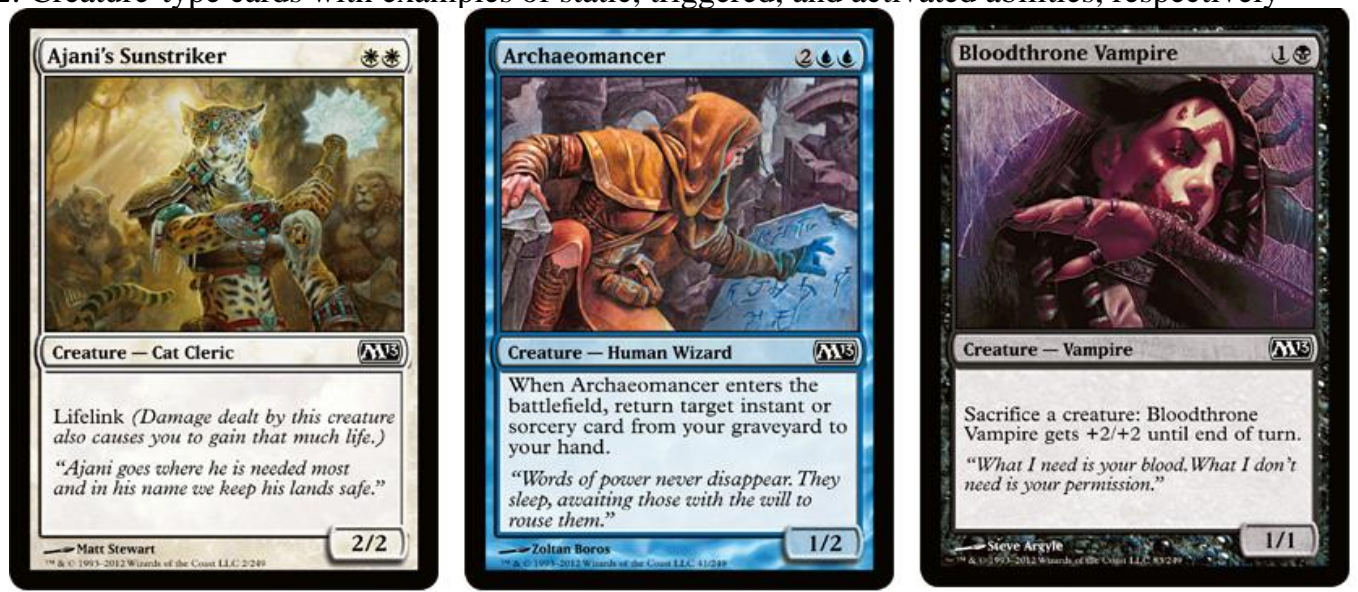

Source: Wizards of the Coast (Gatherer) - $75 \%$ of original size.

FORNAZARI, Meggie Rosar. Localization Practices in Trading Card Games. Magic: The Gathering from English into Portuguese. Belas Infiéis, Brasília, v. 9, n. 4, p. 145-171, jul./set., 2020. e-ISSN: 2316-6614.

DOI: 10.26512/belasinfieis.v9.n4.2020.26387 
Translation constraints include the number of characters available in a card, and font size limits, as well as consistency among all game characteristics such as races $^{1}$, story, rules, and abilities. Keyword abilities in MTG change the rules within a match: they are either static, triggered, and activated (see Figure 2). Static abilities function whenever a card is in play (Ajani's Sunstriker). Triggered abilities function automatically when a condition is met (Archaeomancer). Activated abilities function when players perform an action (Bloodthorne Vampire). Some are summarized in one keyword (such as Lifelink) - common in MTG due to repetition in different sets and to facilitate play.

Within Williams and Chesterman's Translation Studies map, this study lies in the category of Translation and Technology (Localization), intersecting with Text Analysis and Translation ("Comparison of Translations and their Source Texts"). The corpus was analyzed to describe translation practices and policies - both on word and sentence levels - to draw "general principles on how certain things get translated under certain conditions" (Williams and Chesterman, 7). This study also considered Translation Practices (post-service, procedural), rather than (in-service, cognitive) Translation Processes (Williams and Chesterman).

The research questions below underlied the descriptive approach of the present research, as its focus lies on how the translated products was produced, rather than on its reception.

- What are some of the main technical constraints involved in the localization of Magic: The Gathering cards from English to Portuguese? (e.g., font sizes, terms or symbols with no translation, consistency with previous editions, etc.)

- How can possible localization decisions affect the final localized product of MTG?

- How do localization policies affect the translation decisions of a localization team? (e.g., Copyright issues, Marketing, Research \& Development, Creative style guidelines, etc.)

Translation/Localization of Games is a growing academic field with studies on tabletop RolePlaying Games (RPG ${ }^{2}$, video games and second language acquisition (Vidal, Multimodalidade), computer-based Real-Time Strategy (RTS), and MMORPGs ${ }^{3}$, among others. TCGs have specific dynamics and constraints of interest as they rely on declarative speech during play and each player has control of their own actions and consequences. MTG has pioneered in the TCG game format and is a well-established form of entertainment that is 
nonetheless worthy of study. Additionally, research on TCG translation is novel and has not been done - for the En-Pt or for any other ${ }^{4}$. This study opened paths to analyze MTG localizations into other languages, and to analyze the localization of other TCGs. The author's personal experience with playing MTG also sparked curiosity on how the game language is conveyed into Portuguese by wondering about its localization options for terms (such as 'Barreira' instead of 'Muro' for 'Wall') after initial observations during my own participation in the player community, igniting the spark of this study.

\section{Defining Localization}

Chandler and Deming limit the definition of localization to translating linguistic assets, namely "text and voiceover" (4) without altering other game features, leaving that task to internationalization processes. As MTG is not often altered in other aspects, this definition also fits this study adequately. One exception (and an example of internationalization of MTG) is the adaptation of a Chinese taboo of not exposing bones, skeletons, and general images of the dead, which has banned several games in Chinese markets before (Cederskoog). Since 2010, a few humanoid skeletal figures have appeared among the Chinese illustrations of MTG (Wizards of the Coast, Gatherer).

Adapting a product ultimately means to translate each and every text element (Palumbo). Several terms remain untranslated in MTG, such as the creature type "goblin" likely because they refer to cultures that are foreign to Brazil ${ }^{5}$. Such translation also involves "cultural adaptation, as target texts are required to reflect conventions and situations associated with the target market" (71). Not only conventions and standards can be adapted, but also broader cultural adaptations - creating translation practices that sustain the public within comprehensible concepts. For example, the visual aid of illustrations to view a goblin in the MTG mythos, or rules made understandable to a player simply by reading the card, without resorting to a reference book or a judge. MTG is marketed as a game you learn by playing (Wizards of the Coast, M13), and rules are rarely consulted by players; judges study the Magic Comprehensive Rules as they are necessary in official events and tournaments. ${ }^{6}$

As localization services involve large volumes of text to translate, with some degree of repetition, and updates tend to recycle text, such services are usually performed by a team of translators and other professionals that insert translated texts into the interface (Palumbo). Translation is teamwork, including "project manager, terminologist, translator, reviser, DTP specialist, software engineer" (Hartley, 106) throughout the globe, working online via servers. 
The use of Translation Memories (TMs) and glossaries (terminology management systems) is expected in (nearly) every translation task of today. Localization is a modality of professional translation that must follow a pipeline, which improves translational services entirely in "productivity, team-work, coordination and linguistic consistency" (Palumbo, 72). Localizing products or games is of commercial interest because simply selling a product abroad does not guarantee its sales, and Chandler and Deming claim that it is more likely for gamers to buy a game if it is localized into their mother tongue - with approximately 30-70\% of games sales outside its development country, ranging closer to $70 \%$ when players can enjoy a game in their mother tongue.

Localization is, as defined by Palumbo, the linguistic, cultural and technical adaptation of a given product into a specific market. This definition was selected as it comprises all the desired individual features of localization that have been outlined by localization specialists, as seen above. Moreover, since MTG and other TCGs are entertainment, localization is also understood with Bernal-Merino's description of a creative layer of meaning that is set to "facilitate gamers' immersion in order to enhance the player's experience" (6). The volume of

150 translatable text in MTG is surprisingly large, considering its small-sized medium, but it comprises all sources mentioned by Palumbo: websites, user interface (cards), product documentation, and 'collateral' materials (such as product packaging). Translation and localization are used interchangeably in this paper, both meaning localization as defined above.

\section{Defining Internationalization}

Part of the process to create a product that is easily localized into languages with different diacritic marks, text direction, characters, and number treatments (date, time, and currency) is called internationalization, performed in several technical aspects: "user interface (UI), control scheme, game content" (Chandler and Deming, 4). MTG accepts graphic accents and Unicode characters, with Western left-to-right text direction for all languages. Chandler and Deming also stress that if pre-production internationalization is performed with attention to international audiences, the localization process goes about without issues or ruptures. The authors claim that the main objective of internationalizing a product is to produce a final localized version that feels specifically made for the locale, resulting in a game experience that is as similar as possible to the development language version.

Hartley views internationalization as the set of adaptations necessary to fit several linguistic or cultural elements into translation without the need to change design. This includes 
cultural adaptations related to the depiction of violence, for example. Internationalization is a stage before localization (Chandler and Deming), as cultural adaptations must be performed before translation itself, including creating Unicode fonts and character formatting which allow for graphic marks and Asian characters, for example.

\section{Defining Locale}

Esselink points out that the Brazilian locale is of medium range, with long-range locales to which localization is a priority known as FIGS (French, Italian, German, Spanish), plus Japanese. Medium localization priority is Portuguese, Swedish, Norwegian, Danish, and Dutch. Locale is not only the linguistic location of a target text, but also its geographic (and therefore cultural) location (Munday). Pym mentions Brazil as a locale which typically brings the cultural content of media closer to home, therefore domesticating translation (Venuti) to value fluency (Munday).

\section{Defining Translation Policies}

Cronin claims that translation policies should be counteracted and/or manipulated by translators "for their own benefit" (149). Holmes posits that a translation policy scholar should aid in defining "the place and role of translators" (182). Therefore, it is a partial objective in this study to aid in defining the place and role of TCG translators. Toury adds that policies derive from the interface between text and publisher, which is fitting to this study as the game developer/publisher (Wizards of the Coast) is considered. Translation policies are a set of rules created by the development sector or publishing house which must be followed by translators to yield a product that can be either domesticated to value fluency while upholding the cultural background of the target locale, or foreignized to provide players with a sample of foreign cultures through maintaining cultural information pertaining to the source locale - at the same time sustaining the multilingual reality of the game story and universe.

\section{Previous Studies on Localization}

Localization studies have been directed more to software developers than to translators, valuing pre-localization development (internationalization) more than translation itself (Esselink; Chandler and Deming). Localization has recently received more translational focus in essential Translation Studies textbooks, moving the pendulum more towards the translational task than towards how it should fit the industry (Munday; Palumbo). 


\section{Previous Studies on Localization of Games}

The industry has developed Best Practices in Game Localization (Honeywood), developing an idea of culturalization (Edwards): game localization that allows more meaningful engagement of players while ensuring that no offensive or contrasting content is in the game to hinder engagement, listing potential variables for cultural problems (history, religion, ethnicity, and geopolitics). Edwards reinforces that in each game developer, the Localization department should be a part of Research \& Development, one of the most important departments in game development.

Industry and the academia are brought together by Bernal-Merino with statistical data from the Entertainment Software Association in the USA, and bringing awareness of this US\$7-billion media industry that increasingly requires games to be localized. Additionally, he outlines a brief history of electronic games from the pinball machine in 1931 to Spacewar in 1961 and the 1990s boom in video game popularity and acclaim. He also provides a definition of key terms pertaining to games localization, with an emphasis on its translation, localization, or

152 transcreation aspects.

The idea of transcreation is the practice performed by translators when localizing a game, receiving creative liberties to give the final localized product the intuitive feeling that it was originally conceived for its target audience (Mangiron and O'Hagan), with no oddities that could disturb or truncate the game play or narrative experience. The ultimate objective is making a fun game that "feels natural, immersive, and culturally appropriate" (Mangiron and O’Hagan, 6).

\section{Analysis Model}

The model used to analyze the corpus was created by Lambert and Van Gorp - a broad model based on a general and flexible translation theory - adapted for Trading Card Games. Their objective was to characterize textual and translational strategies in two levels: macrostructure (more general) and microstructure (more specific), which are both interrelated in another stage of the analysis named systemic context. Since the model was prepared for literary works, it required an adaptation for trading cards as a textual genre: when the macro level observed "chapter titles, act presentation, and scenes" (211), that internal text division was changed to parts of a card, namely card name, card type, rules text, and flavor text (see Table 1). 
Table 1 - Descriptive translation analysis model

\begin{tabular}{|l|l|}
\hline 1. & Initial data \\
\hline 1.1 & Presence or absence of genre, authors, localizers \\
\hline 1.2 & Metatext (M13 Rulebook) \\
\hline 2 & Macrostructure \\
\hline 2.1 & Text division (card name, type, rules, flavor text) \\
\hline 2.2 & Card name, type, rule and flavor presentation \\
\hline 2.3 & $\begin{array}{l}\text { Internal narrative structure (reflection of plot onto the cards), dramatic plot (prologue, exposition, } \\
\text { climax, conclusion, epilogue - reflected in the cards) }\end{array}$ \\
\hline 2.4 & Author comments (Framing Information) on rules description \\
\hline 3 & Microstructure \\
\hline 3.1 & Lexical choices \\
\hline 3.2 & Dominant grammatical patterns \\
\hline 3.3 & Speech reproduction (direct versus indirect) \\
\hline 3.4 & Narrative, perspective, and point of view \\
\hline 3.5 & Modality (passive versus active, uncertainty, ambiguity) \\
\hline 3.6 & Language levels (archaic, popular, or dialect; game jargon) \\
\hline 4 & Systemic context \\
\hline 4.1 & Macro versus microstructure; text versus theory (norms or models) \\
\hline 4.2 & Intertextual relations \\
\hline
\end{tabular}

Source: Adapted from Lambert and Van Gorp for the context of Trading Card Games.

The macro analysis described whether the localization is oriented predominantly to the target system (acceptable) or to the source system (adequate). Lambert and Van Gorp claim that such dichotomy between adequateness and acceptability is subjective and translations do not tend to be completely coherent in relation to either. This analysis does not list mere differences between source and target, as it follows assumptions that guide corpus-based research in translation studies (Olohan), finding probable and typical features in the MTG translation and interpreting outliers, and understanding the translation practices in the context of Trading Card Games as a genre, with its particular "discourse, text, and rhetorical purpose" (30). This corpus study investigated stylistic conventions and usual translation strategies that are typical of the specific text genre (Olohan) that is a Trading Card Game.

\section{Corpus tools}

Corpus analysis was the empirical method informing this research. A corpus is defined by Olohan as an electronic selection and compilation of texts to be analyzed through specific corpora software. These texts can be either written, spoken, or multimodal. Corpus methods were chosen due to their multimodality applicable to cards and their research practicality when digitally dealing with authentic material, as well as their fruitful analyzes of linguistic (and translational) performance rather than competence. Corpus-based research enables us to visualize externalized language and to analyze phenomena that can be observed through the 
finished product, outside the translator's mind (Leech). This study did not observe real-time processes during this type of translation service.

The corpus assembled is bilingual, parallel, and static - that is, one fixed collection of cards that depicts the game at a specific point in its time, storyline, and history (the Magic 2013 Core Set). It aimed at performing corpus-driven research on Trading Card Games as textual genre, since there was no pre-existing theoretical description yet. Both English and Portuguese versions of all MTG cards are available online at its official database website, Gatherer, free of charge, in both image and text. The 2013 Core Set has 249 cards, and a bilingual corpus was constructed by gathering the textual spoiler from both English and Portuguese image files, for a total of 498 cards, along with its metatext (the Basic Rulebook also available free of charge in the game website) in both languages. Text alignment was performed manually using Notepad++. The corpus is available online within the COPA-TRAD ${ }^{7}$ system.

\section{Analytical Procedures}

Macrostructure features of the translated cards were collected and analyzed to observe

154 how the game was identified as a translation, how translators and localizers received credit, and its recognition as a translated text in relation to "linguistic interference, neologisms, sociocultural features" (Lambert and Van Gorp, 206), as well as its metatext. This first-level analysis provided insight on the translation practices adopted for MTG, and parts of the corpus were selected for further micro analysis. Micro analyses involved collecting statistical data for analysis about insertions, deletions, explicitations, or alterations of information within the text, thus providing data on consistency of adding or deleting information, as well as on further and more precise visualization of translation practices permeating this type of localization task. When necessary, these consistencies were categorized and related to one another.

Corpus alignment was performed manually by segment using parallel concordancing software WordSmith 3.0. Queries were sorted out in different ways to observe usage patterns, and frequency lists were retrieved to check for ability keywords and their correspondents in Portuguese. Collocations were observed, for example, as to which verbs are followed or preceded by card abilities, with a collocation horizon set to one word to the left, and one to the right. Semantic prosody was analyzed in terms of positive or negative connotation given to certain collocates (e.g., for verbs following the term 'creature'). 


\section{Data Analysis}

The corpus created for this study was classified according to Fernandes as synchronic (one point of the game in time), specialized (TCG), and unidirectional (En-US to Pt-Br). Criteria for selecting the Magic 2013 Core Set were: its release in June 2012, during the window of analysis; its typicality as a game translated by a third-party language service provider (Alpha CRC); its mode and medium as the digitalized version of cards printed to be played (with all rights reserved to Wizards of the Coast, although research findings are my own); and its overall corpus size of 51,945 words. Corpus sizes should fit their research objectives to analyze the phenomena (Fernandes). Although cards are small, they have considerable amounts of text: 498 cards have 18,540 words in total - with an average of approximately 37 words per card. However, average number of words per card differs for each language: 35 words per card in English, and 40 words per card in Portuguese. This is consistent with the usually longer length of localized text (Chandler and Deming). The metatext comprises 32,955 words (63.4\% of total corpus size).

\section{Presence or absence of genre, authors, localizers}

The packaging can be used to analyze a manner of heading and bibliographical information, which is fully localized. The genre of Trading Card Games is not clearly stated in booster packs (a blind bag with 15 semi-random cards inside: 1 Land card, 10 Common cards, 3 Uncommon cards, and 1 card that may be either Rare or Mythic Rare, and sometimes an extra premium foil card of any rarity, a token card for temporary creatures, or advertisements about present or future expansions as well as other MTG products). Due to its importance as its main product, the booster pack is representative of the genre and was considered as an analogue to a book cover. Localized booster packs are explicitly stated as a translation, with their language printed on the upper left corner of boosters, and the genre of Trading Cards is explicit in its contents: ' 15 estampas ilustradas'. It is possible to assume that the term 'cartas' was not used due to poor connotations of casino games (Blackjack and Poker), or even divination (Tarot). However, in Brazil the word 'estampa' is usually collocated with clothing (printed T-shirts), while 'ilustradas' refers to visual aids in books and magazines - which fits Trading Cards as illustrations aid in-game; a more fitting suggestion could be 'Cartas Ilustradas'. However, illustrated cards could trigger a gambling connotation from 'cartas', while adding the narrative idea of visual aids commonly seen in children's literature.

Except for the name of the game, all other packaging information is translated; this indicates that the product is translated with source-system orientation, which Lambert and Van 
Gorp conceptualize as an adequate translation - fitting the grammar needs of Portuguese language, but not drifting very far from the most literal translation options available - even if those translational choices may not be very intuitive. The credits section of our metatext, the Magic 2013 Basic Rulebook provides more data, with explicit mention and crediting to translation and localization as two separate functions. Both translators are Brazilian (one is a known MTG judge and owner of a hobby store in Porto Alegre), and this indicates that the translators are native speakers of Brazilian Portuguese and reside in the country, which is important to have constant contact with the country's cultural expectations (Chandler and Deming). However, the localizers credited are not Brazilian, which can imply their responsibility in project management and other technical activities which pertain to localization. There is also a possible translation error in the Portuguese Rulebook, as Richard Garfield is the original game designer of MTG, and not its original graphic designer; the same credits are mentioned eight lines below, then with the rightful original graphic designers. This error may have derived from improper recycling of translation memory units, and helps in evidencing that Computer-Assisted Translation (CAT) tools are used.

156 There is metatextual information in the cards in relation to game mechanics, but they are not translation footnotes as they appear in the original. Game mechanics would be keywords used in-game to mean a certain rule occurs during play: for example, in the keyword mechanic 'Trample', an attacking creature with power 6 blocked by a creature with toughness 4 tramples over the blocking creature, killing it on the way, and dealing the remaining 2 damage to the defending player. This description is called reminder text, and it can be seen in italics and in parenthesis, next to a mechanic keyword.

\section{Metatext: the Magic 2013 Basic Rulebook}

The type-token ratio of the metatext was 30.53 in English and 32.54 in Portuguese, which was close to expectations although the text is relatively short (approximately 16,000 words in each language), due to the repetition of keyword abilities and game rules, and because half the Rulebook is a game glossary. Additionally, the higher type-token ratio of the Brazilian text indicates higher lexical density typical of the language (Fernandes).

For each language, frequency lists were analyzed before alignment and nongrammatical words with frequency over 100 are listed in Table 2. Each respective plural of nouns was merged with its singular lemma. From this list, one word which calls more attention is 'can' (and its expected correspondence, 'pode'), as it is the only verb with over 100 
occurrences in each list. All possible conjugations of 'pode' in Portuguese have been included as its lemmas, and 'can't' has been added as a lemma of 'can'.

Table 2 - Most frequent non-grammatical words (over 100 occurrences each) in each language

\begin{tabular}{c|c|c|c}
\hline \multicolumn{2}{c|}{ En-Rulebook } & \multicolumn{2}{c}{ Pt-Rulebook } \\
\hline Word & Frequency & Word & Frequency \\
\hline you & 425 & criatura & 294 \\
\hline creature & 295 & você & 291 \\
\hline card & 271 & cards & 263 \\
\hline ability & 249 & habilidade & 259 \\
\hline can & 190 & mágica & 180 \\
\hline spell & 143 & pode & 148 \\
\hline player & 133 & jogador & 135 \\
\hline game & 130 & mana & 124 \\
\hline mana & 125 & dano & 116 \\
\hline damage & 113 & jogo & 116 \\
\hline-- & -- & terreno & 103 \\
\hline-- & -- & tipo & 101 \\
\hline
\end{tabular}

Source: created by the author.

The most frequent co-occurrences of these frequent terms (over 10 each) with collocational horizons immediately before and after 'can' and 'pode' were obtained (Table 3 ). The analysis was limited to the first word next to 'can'/"pode' as most occurrences were accounted for in this collocational horizon.

Table 3 - Most common collocates with the word can (collocational horizon 1L and 1R).

\begin{tabular}{c|c|c|c}
\hline \multicolumn{2}{c|}{ En-Rulebook } & \multicolumn{2}{c}{ Pt-Rulebook } \\
\hline $\boldsymbol{x}$ can & can $\boldsymbol{x}$ & $\boldsymbol{x}$ pode & pode $\boldsymbol{x}$ \\
\hline you (90) & be (37) & você (48) & ser (29) \\
\hline player (12) & cast (19) & não (29) & conjurar (12) \\
\hline creature (11) & have (15) & só (16) & ter (10) \\
\hline-- & play (12) & -- & ter \\
\hline
\end{tabular}

Source: created by the author.

After manual alignment, 161 segments $^{8}$ were selected based on their use patterns to assess certain specific terms and correspondents, based on the four types of translational correspondence (Thunes): literal, word-by-word translation (type 1), near-literal translation with grammatical insertions, deletions, or adaptations (type 2), syntactic but not semantic changes (type 3), and both semantic and syntactic differences in the target text (type 4). Segments were selected as the unit of this analysis, corresponding to short sentences or parts of longer sentences cut automatically by Wordsmith to be only one line long around the collocate. Some segment intersection among the 161 segments is due to double concordances; for 
example, the expression 'you may cast' corresponds both to concordance with 'you' and with 'cast').

Most co-occurrences were categorized as Type 2 in the Thunes's framework - nearliteral translation with differences in word order and use of grammatical words due to syntactic restrictions which are pertaining to Brazilian Portuguese that do not belong in the English language. Although many segments are $100 \%$ similar, they are in different sections within the Rulebook and are considered as separate occurrences. It is possible to infer the use of Translation Memory (TM) systems in this translational task to uphold consistency between each step and phase of the game, as explained in the Rulebook. The translational pattern with Type2 majority is expected due to the metatext as a genre: A Rulebook has a message of normative character to convey (Gile), comparable in due proportion to legal text. Although the Basic Rulebook was available as source for players to solve game issues, in official sanctioned events the consultation of rules is done verbally by consulting judges - volunteers tested and certified by Wizards of the Coast with ample knowledge not only of Basic but also of Comprehensive Rules (a 360-page tome directed to Magic judges only, also available free of charge at the game official website).

This brief analysis provides insight on some discrepancies found in Table 3, where the frequency of several co-occurrences is quite reduced in Portuguese in comparison with English. There are additions of 'so' in several terms in which there is no correspondence in English, ( 2 instances of 'only can' for 16 of 'só pode'). By altering the collocational horizon to 'only $\mathrm{x}$ can' (2) and 'can x only' (9), it is possible to find 11 more occurrences, but 3 remain with no correspondence found. In those instances, 'só' could have been added as Framing Information, that is, information added by translators to clarify potentially difficult terms (Gile).

The absence of Thunes's Types 3 and 4 in the metatext indicates that choices with different syntactic (Type 3) and/or semantic representations (Type 4) have not been privileged. This is another indication that the translation is produced to be adequate (Lambert and Van Gorp) to linguistic demands only, without concern for public acceptance or usage. Pragmatic equivalence seems to be privileged above all, perhaps partly due to the text genre, or product localization briefing.

\section{Text division (card name, type, rules, reminder, flavor text)}

A fitting illustration of the card text internal division can be found in its metatext (see Figure 3 ), featuring and explaining what text pertains to each part of a card. This visual structure is 
essentially the same since its origins, but design was changed in the game's Seventh Edition with some design backgrounds made easier to read in comparison to Classic-design cards. Since the back of the cards has never been changed, cards from all editions can be used in some play formats (Vintage and Legacy).

Figure 3 - Parts of a MTG card, as explained in the Rulebook (extract of page 5)

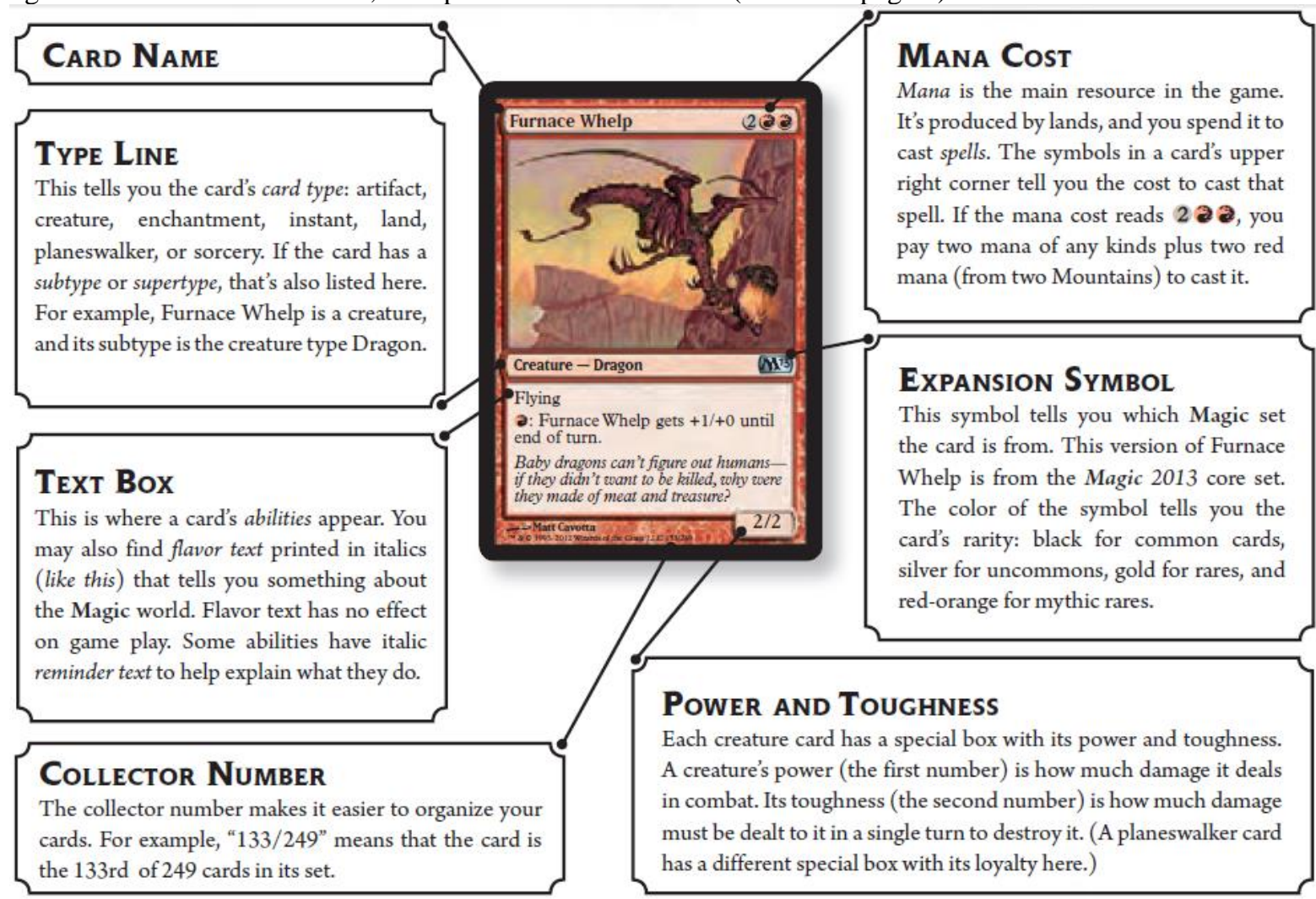

Source: Wizards of the Coast (Gatherer).

\section{Card name, type, rules, reminder text, and flavor presentation}

In Figure 3, four sections (Mana Cost, Expansion Symbol, Power and Toughness, and Collector Number) are not translated as they are either numbers or non-verbal information. Sections pertaining to translation are Card Name, Type Line, and Text Box (in turn separated in Card Abilities, Reminder Text, and Flavor Text). For in-game consistency, the text translated within Type Line, Card Abilities, and Reminder Text is usually more formulaic and less prone to being changed throughout editions, with some translation options unchanged since the game's Fourth Edition (the first translation ever made into Brazilian Portuguese). Card Names and Flavor Text usually accept greater creative endeavors, with careful checking of the 20,000 previously released cards in order to prevent card name repetition for different cards. 


\section{Internal narrative structure (story references in cards), dramatic plot (prologue, exposition, climax, conclusion, epilogue - as referenced in cards)}

In play, plot understanding is not fundamental or necessary. Any reference to the game plot story is implied in each card by what it performs in play, but it is only clearly stated in its flavor text. However, Core Sets have less plot as they transitioned between the previous narrative block and the next. In the case of Magic 2013, the Innistrad block was being wrapped up: based on European and particularly Germanic Grimm-like horror, this plane was one of the most popular among players, having broken sales records. M13 was the Core Set that prepared the ground for the Return to Ravnica block - a city-world governed by ten guilds, each with their own agenda, which had already been a narrative block years before. Both planes can be glimpsed through some of the M13 cards, as if flowing from one plane into the other. This strategy of using a Core Set to stabilize the narratives between blocks was used since 2010, and before that the main narrative concentrations were called Editions, with less regularity in yearly releases especially during its first four years of the game's existence. In the view of translation, the flavor text is where most creativity can flow, and more local transcreation could be 160 performed - however, this chance does not seem to be taken. Most translated flavor seems to be produced to be adequate, but could be produced to be acceptable at least in this section, where narrative matters more than game rules.

\section{Lexical choices}

The most frequent lexical choices in this corpus are in Figure 4. They pertain to four essential semantic groups (Table 4): dueling, magic, metagame, and its collecting element. Words with no semantic category ('mesmo', 'qualquer') were considered as grammatical words that were not properly ignored by the system.

Figure 4 - Word cloud with the 50 most frequent words in the corpus and their respective frequencies

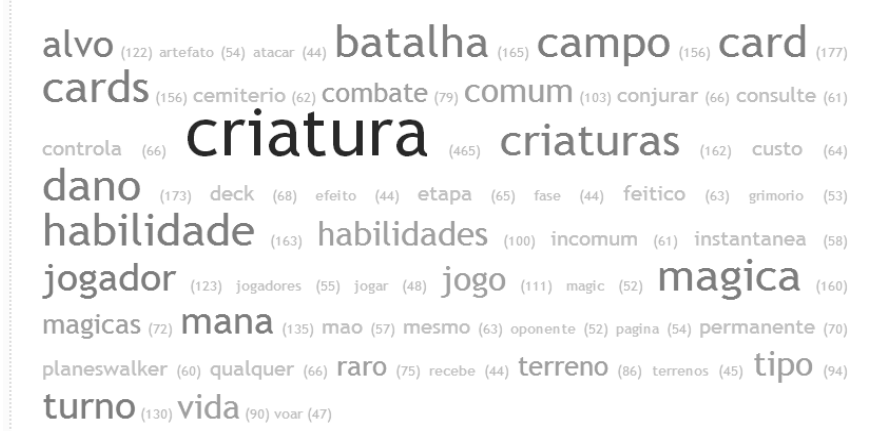

Source: created by the author at tagcrowd.com.

FORNAZARI, Meggie Rosar. Localization Practices in Trading Card Games. Magic: The Gathering from English into Portuguese. Belas Infiéis, Brasília, v. 9, n. 4, p. 145-171, jul./set., 2020. e-ISSN: 2316-6614.

DOI: 10.26512/belasinfieis.v9.n4.2020.26387 
Note: Grammatical words of Brazilian Portuguese were ignored.

Table 4 -Semantic sorting of the 50 most frequent words in the corpus

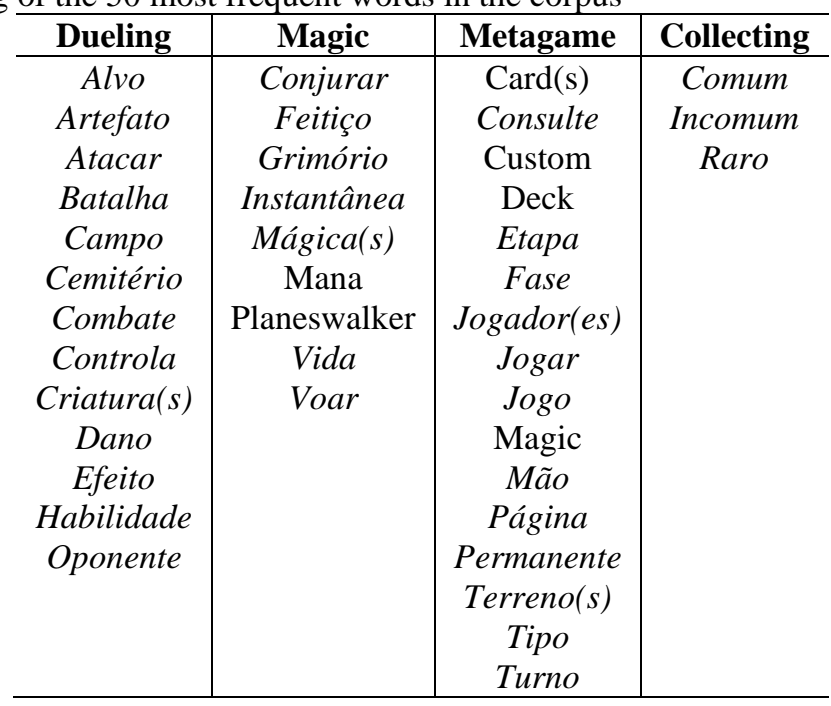

Source: created by the author.

Note: Semantic groups were defined by the author

The most frequent words in the corpus do not reflect the sophisticated vocabulary pertaining to MTG as a Research and Development prerogative in its development language (Rosewater). This is part of R\&D minor objectives in game design: to expand the players' vocabulary and introduce them to interesting, uncommon, and rare words of English language.

By analyzing the corpus especially on its creative sections (Card Name and Flavor Text), this is also apparent in Portuguese. Table 5 shows some examples of uncommon words used in English and Portuguese card names from the corpus and aids in reinforcing the element of fantasy in which MTG stories develop.

Table 5 - Ten sample card names from the studied corpus which exemplify the sophisticated vocabulary used in both languages, implying the use of such vocabulary as one localization practice.

\begin{tabular}{c|c}
\hline English & Portuguese \\
\hline Spiked Baloth & Baloth Espiculado \\
\hline Elderscale Wurm & Vorme Vetusto \\
\hline Welkin Tern & Carrago Celeste \\
\hline Roaring Primadox & Primadox Rugidor \\
\hline Hellion Crucible & Crisol de Avernais \\
\hline Void Stalker & Espreitador do Vácuo \\
\hline Unsummon & Esconjurar \\
\hline Goblin Arsonist & Goblin Pirômano \\
\hline Rootbound Crag & Penhasco do Raizame \\
\hline Duress & Coagir
\end{tabular}

\section{Dominant grammatical patterns}


Most verbs give instructions on how rules are enacted in play; verbs appear in the imperative when rules are obligatory, and in conditional forms when players choose their activation. This is clear in the Text Box (Card Abilities and Reminder Text). However, mechanics keywords present less grammatical consistency (examples of mechanic keywords and their respective reminder text from the corpus in both languages are in Table 6). Mechanic keywords are used to summarize card abilities which are frequently used in play that enact specific effects. Although that is dependent on the amount of text in the box, flavor text is not provided for cards that need more room for rules. Font sizes can be reduced to fit more text - which also occurs in the development language when necessary.

Table 6 - Ten sample mechanics keywords from the corpus, accompanied by their reminder text

\begin{tabular}{|c|c|}
\hline English & Portuguese \\
\hline $\begin{array}{c}\text { Trample (If this creature would assign enough damage } \\
\text { to its blockers to destroy them, you may have it assign } \\
\text { the rest of its damage to defending player or } \\
\text { planeswalker.) }\end{array}$ & $\begin{array}{c}\text { Atropelar (Se esta criatura fosse atribuir dano } \\
\text { suficiente para destruir seus bloqueadores, você } \\
\text { pode fazer com que ela atribua o resto de seu dano } \\
\text { ao planeswalker ou jogador defensor.) }\end{array}$ \\
\hline $\begin{array}{c}\text { First strike (This creature deals combat damage before } \\
\text { creatures without first strike.) }\end{array}$ & $\begin{array}{c}\text { Iniciativa (Esta criatura causa dano de combate } \\
\text { antes das criaturas sem iniciativa.) }\end{array}$ \\
\hline Reach (This creature can block creatures with flying.) & $\begin{array}{c}\text { Alcance (Esta criatura pode bloquear criaturas } \\
\text { com voar.) }\end{array}$ \\
\hline Vigilance (Attacking doesn't cause this creature to tap.) & $\begin{array}{c}\text { Vigilância (Esta criatura não é virada para } \\
\text { atacar.) }\end{array}$ \\
\hline $\begin{array}{l}\text { Exalted (Whenever a creature you control attacks } \\
\text { alone, that creature gets }+1 /+1 \text { until end of turn.) }\end{array}$ & $\begin{array}{c}\text { Exaltado (Toda vez que uma criatura que você } \\
\text { controla ataca sozinha, ela recebe }+1 /+1 \text { até o } \\
\text { final do turno.) }\end{array}$ \\
\hline $\begin{array}{l}\text { Regenerate (The next time this creature would be } \\
\text { destroyed this turn, it isn't. Instead tap it, remove all } \\
\text { damage from it, and remove it from combat.) }\end{array}$ & $\begin{array}{c}\text { Regenere (Na próxima vez em que esta criatura } \\
\text { seria destruída neste turno, ela não será. Em vez } \\
\text { disso, vire-a, remova todo o dano dela e remova-a } \\
\text { do combate.) }\end{array}$ \\
\hline $\begin{array}{c}\text { Lifelink (Damage dealt by this creature also causes you } \\
\text { to gain that much life.) }\end{array}$ & $\begin{array}{c}\text { Vínculo com a vida (O dano causado por esta } \\
\text { criatura faz com que você ganhe uma quantidade } \\
\text { equivalente de pontos de vida.) }\end{array}$ \\
\hline Defender (This creature can't attack.) & Defensor (Esta criatura não pode atacar.) \\
\hline $\begin{array}{c}\text { Equip (Attach to target creature you control. Equip } \\
\text { only as a sorcery.) }\end{array}$ & $\begin{array}{l}\text { Equipar (Anexe à criatura alvo que você controla. } \\
\text { Equipe somente quando puder conjurar um feitiço.) }\end{array}$ \\
\hline $\begin{array}{c}\text { Flying }^{9} \text { (This creature can't be blocked except by } \\
\text { creatures with flying or reach.) }\end{array}$ & $\begin{array}{l}\text { Voar (Esta criatura só pode ser bloqueada por } \\
\text { criaturas com a habilidade de voar ou alcance.) }\end{array}$ \\
\hline
\end{tabular}
Source: Created by the author.

Note: All text presented here is exactly how it is presented in cards, without editing or revision

The table shows the grammatical inconsistency in the translation of keyword abilities. Three ability types are present in these examples: static abilities (abilities that are always functioning, as long as a card with the ability is in play), triggered abilities (abilities that are only functioning depending on the occurrence of a specific effect in the game), and activated abilities (abilities which require certain player actions to function, such as paying mana, sacrificing creatures, 
discarding or buying cards, and so on). Activated abilities in Table 6 are Regenerate and Equip; Exalted is a triggered ability, while the remaining others are static abilities.

Since they serve different functions in play, they should receive different grammatical treatment: triggered abilities are translated as adjectives because they become, say, exalted, when and only when something happens in play. Activated ability keywords are translated as verbs because they are actions to be performed. Static keyword abilities are not actions to be performed; they are innate characteristics of each card and should be translated as nouns only. This grammatical class would imply that this is an ability the card intrinsically has and that can be gained or lost depending on the effect of certain cards. However, the development language for static abilities is grammatically ambiguous (e.g., flying can be either a verb or an adjective depending on the context). This may be why some static ability keywords were translated as verbs in the infinitive; abilities such as Flying and Trample have been in use since the very beginning of the game (Alpha Edition) and also since its first localization into Brazilian Portuguese in its Fourth Edition.

It is implicit from Table 6 that more recent keywords were localized according to the observations above, as the remaining static abilities (Iniciativa, Alcance, Vigilância, and Vinculo com a vida) are translated as nouns. This reflects their intrinsic feature and allows for these abilities to be gained or lost depending on certain card effects - for example, a card can say "Target creature gains first strike until end of turn" ( "A criatura alvo ganha iniciativa até o final do turno"), providing an ability temporarily.

\section{Speech reproduction (direct versus indirect)}

Flavor text is the card section in which the strongest narrative elements are found; in which character quotes are often present, featuring both large and small characters of the MTG multiverse, from Planeswalkers to Creatures. For example, the Creature named War Priest of Thune has a quote in a card named Faith's Reward, using direct speech in both languages.

\section{Narrative, perspective, and point of view}

The flavor text section also has narration, seen as omniscient narration or camera narration from the point of view of one or more characters, and sometimes as fictional citations of an in-game publication, and seldom real-life or literary references. This multiplicity of perspectives reinforces the multiplicity of characters and worlds involved in MTG, which is usually conveyed with similar accuracy in flavor translation. The translation of culture-specific flavor 
text maintains real-world or literary references even though translations are still performed as adequate. This is one point where a shift to appropriate translation could make the adaptation of real-world references stronger, easier to recognize and relate, and therefore more special for player experience.

\section{Modality (passive versus active, uncertainty, ambiguity)}

Ambiguity is reduced to a minimum in the localization of a rules-based game such as TCGs. However, doubts can arise during play especially when two or more cards are in action simultaneously (what the Basic Rulebook calls 'the stack'). Doubts can be solved by a judge during sanctioned events, by other players, or by consulting the discussion section of a card in Gatherer, the MTG official database. Translation has brought translation errors that caused judges to release errata for cards as described in the development language, and not as translated due to translation errors that changed rules.

\section{Language levels (archaic, popular, or dialect; game jargon)}

164 Although the game is marketed for 13-years-old or above, the language level used in MTG is not facilitated for the reading capacity of preteen audiences. That may be because player age averages for the general gamer is of approximately 30 (Bernal-Merino), but also to reinforce the fantasy environments on which the game is narratively based. Additionally, the language level of the game has a strong element in its jargon, as it functions as metalanguage about the game. MTG jargon would include card or match elements (Figure 5), and game mechanic keywords (Table 6). Figure 5 lists the parts of a turn in a match (Basic Rulebook, 2012). Translation choices also point to a more adequate translation trend, especially because of the algorithmic character of these elements in play. This also implies the use of TM due to the similarity between segments in both lists. 
Figure 5 - Parts of a turn during a match, extracted from the Basic Rulebook, and its localization to Portuguese

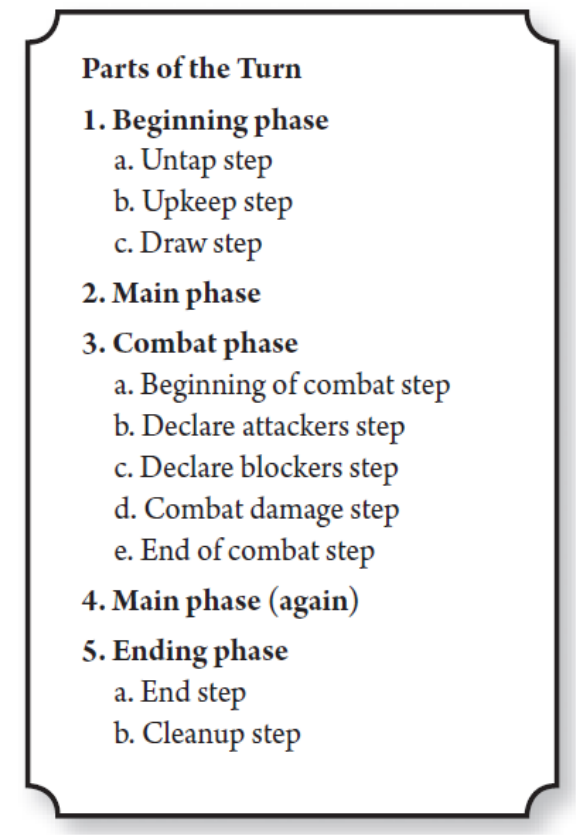

Partes do turno

1. Fase inicial

a. Etapa de desvirar

b. Etapa de manutenção

c. Etapa de compra

2. Fase principal

3. Fase de combate

a. Etapa de início de combate

b. Etapa de declaração de atacantes

c. Etapa de declaração de bloqueadores

d. Etapa de dano de combate

e. Etapa final de combate

4. Fase principal (novamente)

5. Fase final

a. Etapa final

b. Etapa de limpeza

Source: Wizards of the Coast (Gatherer).

\section{Macro versus microstructure; text versus theory (norms or models)}

Both micro and macro structure data have indicated consistency in producing adequate translations in the Trading Card Game, due to its algorithmic function in play. Additionally, more transcreative space lies in creative sections: Card Name and Flavor Text. However, the translated product of creative sections is still adequate when it could be acceptable to cultural expectations. For example, idioms can be translated differently when adequate translations do not reflect them culturally.

\section{Intertextual relations}

Although intertextual relations in the MTG multiverse are also related to flavor text, other forms of intertext were not translated. Weekly short stories in the official MTG website and novels previously released about some narrative blocks have not been translated. Digital comic books that had been translated into Portuguese (although the last two issues appear only in Spanish) were discontinued in 2009. However, other intertextual relations could be drawn among cards in a set using quotes or references to planeswalkers or legendary creatures: for example, Crusader of Odric refers to Odric, Master Tactician in its flavor text, and this also indicates fruitful combination of both cards in play. Translation maintains intertextual references accordingly. 


\section{Technical constraints}

It is possible to note font reduction in $41 \%$ of the Portuguese-localized cards of the analyzed corpus (103 out of 249). Usually 20-30\% of text are larger in translated text (Chandler and Deming), taking up more space; however, it is not clear if this is due to explicitation or due to language or genre specificities. Font sizes were reduced to fit the same Message in Portuguese cards. This is a common practice for texts localized to French or German, resulting in text approximately 30\% longer when translated from English (Esselink). This is likely an automated response to the larger amount of text, as translated card text can be added onto card templates to fit into previously allocated spaces and the template adapts font sizes automatically, as seen in informal card-creating software used to create card parodies of no playing value or custom playable tokens of no selling value.

Icons are a widespread technique used by game developers to simplify certain meanings within a game (Chandler and Deming); in MTG, certain symbols were created and are in-game canon (the mana and card-tapping symbols known as WUBRGT). They have specific meaning in-game, serving as nonverbal information that simplifies meanings and the translation of these meanings. This also applies for card copyright information, collector number, and expansion symbol which are untranslatable elements that carry meaning with numbers or symbols.

\section{Translation Policies}

The following possible constraining translation policies could be derived drawing on the findings (Magic 2013 Core Set) in English and Portuguese:

1. Translation seems to be produced to create a product that is adequate as text in Brazilian Portuguese, which can make the text seem truncated and not acceptable in its tenor of being written to be played,

2. Due to flavor narrative of fictional fantasy universes, translation may be discouraged to produce real-world culturally-specific references, unless the development language has already done so; in that case, they are still translated to be adequate when they could be translated to be acceptable in the Brazilian cultural point of view, in which sometimes creative flavor can be lost in humor or meaninglessness, 
3. More recent mechanic keywords for static abilities were translated as nouns, sustaining meaning as an ability that is innate, received, or lost; activated abilities are translated as verbs as they are enacted by play,

4. Text previously translated is not changed to uphold rules consistency; mechanic keywords that do not follow grammatical consistency to rules and were translated in previous editions could be changed to prevail grammatical consistency over ingame consistency, causing as little impact on the game as possible,

5. Font sizes may not be an issue that translators actively decide on, as they may be automatically adapted; however, TCG translators should keep this in mind and adopt translation strategies whenever fitting,

6. Game text (Card Type, Rules Text, Reminder Text) is more formulaic and algorithmic, whereas creative text (Card Name and Flavor Text) is not and therefore has room for transcreation.

The policies found can be extrapolated for the TCG genre, although future studies should analyze other TCGs to find consistencies (and inconsistencies) with MTG, in order to check if the present conclusions would be reproducible.

\section{Limitations of the study and suggestions for further research}

Due to time constraints, only one set of cards was analyzed in this study. Even though the corpus is relatively representative of its genre due to the large amount of text per card, more sets of MTG could provide sturdier results - perhaps with all expansions in a narrative block, to reach other levels of analysis such as narrative translation studies. This can transform the corpus from static to dynamic, adding either previous or future editions, or even other TCGs. This would be of academic interest for longitudinal analyses of the genre as to linguistic and translational evolution; for example, the term planeswalker had been previously ${ }^{10}$ translated to planinauta only to appear untranslated again more recently, which may be due to copyright.

Although TCGs are multimodal, the text-only corpus was analyzed, even though all card image files were saved, in both languages. In addition, failure to upload the corpus onto COPATRAD was due to technical problems with the website system administration. Each card image should be added onto the corpus as visual aid in design, text positioning, and other details to keep the text as authentic as possible (Leech). Image files are academically interesting as card 
illustrations can be used for other multimodal studies (Fornazari), with room for further multimodal studies in relation to, for example, gender and ethnic representation in cards.

Scholars specialized in other languages could add other localizations of MTG onto the corpus for analysis, transforming it into a multilingual corpus with any of the other nine languages to which the game is localized and enable comparative translation studies among, say, Portuguese, Spanish, Italian, and French to derive best practices for Romance language localization of TCGs. Other aspects of localization outside corpus-based studies could give voice to translators involved with such type of task if their Non-Disclosure Agreements so allows it, using semi-structured interviews to create a TCG translator profile, and to assess whether the translation practices observed in this study are in fact part of their everyday work. Finally, reception studies can be performed with TCG players to evaluate how the localization choices are used (or not), and possible reasons behind it, perhaps also using semi-structured interviews to create a player profile as well as recording authentic matches to analyze the use of translation options (or lack thereof) during play.

\section{ACKNOWLEDGEMENTS}

To professor Lincoln Fernandes for supervising this study, to $\mathrm{CNPq}$ for financial support; to Wizards of the Coast, Devir, and Alpha CRC for answering countless questions from an official standpoint. Lastly, to the MTG player community.

\section{REFERENCES}

Bernal-Merino, Miguel A. "On the Translation of Video Games." The Journal of Specialized Translation, v. 6, 2006, pp. 22-36.

Bulfinch, Thomas. O Livro de Ouro da Mitologia, translated by David Jardim Júnior, Ediouro, 2002

Cederskoog, Karin. "When to Forgo the Culturalization of Video Games: Contextualizing Globalization within the Mobile Marketplace." Gamasutra, 02 July 2012,: http://www.gamasutra.com/blogs/KarinESkoog/20120702/173371/When_to_Forgo_the_Cult uralization_of_Video_Games_Contextualizing_Globalization_within_the_Mobile_Marketpla ce.php. Accessed on: 02 Mar. 2020.

Chandler, Heather Maxwell, and Stephanie O'Malley Deming. The Game Localization Handbook, 2nd edition, Jones \& Bartlett Learning, 2012.

Coletti, Bruna Luizi. "COPA-MUM - A importância do Domínio da Linguagem Especializada na Localização de Roleplaying Games.” Pesquisas em Games: Ideias, Projetos e Trabalhos, 
edited by Cristiane D. Vidal, Isaque M. Elias, and Viviane M. Heberlep, UFSC/LLE/CCE, 2013, pp. 57-67.

Cronin, Michael. "The Cracked Looking Glass of Servants: Translation and Minority in a Global Age." The Translator, vol. 2, no. 4, 1998, pp. 145-162. doi: https://doi.org/10.1080/13556509.1998.10799017

Edwards, Kate. "Culturalization: The Geopolitical and Cultural Dimension of Game Content." Trans, vol. 15, 2011, pp. 19-28.

Esselink, Bert. A Practical Guide to Localization, John Benjamins, 2000. doi: https://doi.org/10.1075/liwd.4

Fernandes, Lincoln P. Brazilian Practices of Translating Names in Children's Fantasy Literature: A Corpus-Based Study. Unpublished PhD dissertation, Universidade Federal de Santa Catarina, 2004.

Fornazari, Meggie R. "Magic the Gathering sob a Ótica da Gramática Visual.” In-traduções, vol. 5, 2013, pp. 13-28.

Gile, Daniel. "Fidelity in Interpretation and Translation." Basic Concepts and Models for Interpreter and Translator Training, vol. 8, 2009, pp. 52-78. doi: https://doi.org/10.1075/btl.8 Hartley, Tony. "Technology and Translation". The Routledge Companion to Translation Studies, edited by Jeremy Munday, Routledge, 2009, pp.106-127.

Holmes, James. "The Name and Nature of Translation Studies." The Translation Studies Reader, edited by Lawrence Venuti, Routledge, 1972, pp. 172-185.

Honeywood, Richard. Best Practices in Game Localization. International Game Developers Association, 2011, http://englobe.com/wp-content/uploads/2012/05/Best-Practices-for-GameLocalization-v21.pdf. Accessed on: 02 Mar. 2020.

Lambert, José, and Hendrik Van Gorp. "Sobre a Descrição de Traduções." Literatura \& Tradução: Textos Selecionados de José Lambert, edited by Andréia Guerini, Marie-Hélène Torres, and Walter Carlos Costa, 7Letras, 1985, pp. 197-213.

Leech, Geoffrey. "Corpora and Theories of Linguistic Performance." Directions in Corpus Linguistics: Proceedings of Nobel Symposium, edited by Jan Svartvik, Mouton de Gruyter, 1992, pp. 105-122.

O'hagan, Minako, and Carmen Mangiron. "Game Localisation: Unleashing Imagination with 'Restricted' Translation." The Journal of Specialized Translation, vol. 6, 2006, pp. 10-21. Munday, Jeremy. The Routledge Companion to Translation Studies, Routledge, 2009.

Olohan, Maeve. Introducing Corpus-based Translation Studies, Routledge, 2004. https://doi.org/10.4324/9780203640005

Palumbo, Giuseppe. Key Terms in Translation Studies, Continuum, 2009. 
Pym, Anthony. "Venuti's visibility" (Review of The Translator's Invisibility). Target, vol. 8, no. 1, 1996, pp. 165-177. doi: https://doi.org/10.1075/target.8.1.12pym

Rosewater, Mark. "Mark Rosewater Archive." Daily MTG, https://www.wizards.com/Magic/Magazine/Archive.aspx?author=Mark\%20Rosewater.

Accessed on: 02 Mar. 2020.

Thunes, Martha. "Classifying Translational Correspondences." Corpora and Cross-Linguistic Research: Theory, Method and Case Studies, edited by Stig Johansson and Signe Oksefjell, Rodopi, 1998, pp. 25-50.

Toury, Gideon. "The Nature and Role of Norms in Translation." The Translation Studies Reader, edited by Lawrence Venuti, Routledge, 1995, pp. 198-212.

Venuti, Lawrence. The Translation Studies Reader, Routledge, 2012.

Vidal, Cristiane Denise. Multimodalidade e Traduções Funcionais para Investigar a Aquisição de Segunda Língua em Gamers. Unpublished PhD dissertation, Universidade Federal de Santa Catarina, 2011.

Vidal, Cristiane Denise. A Experiência da Localização de Games da Blizzard ao português do Brasil: um Estudo de Caso. Unpublished postdoctoral report, Universidade Federal de Santa 170 Catarina, 2013.

Vidal, Cristiane Denise, and e Isaque M. Elias. "When Brazil Enters the Koprulu Sector: The Starcraft II Localized into Brazilian Portuguese.” Proceedings of XI SBGames, 2012, pp. 114124.

Williams, Jenny, and Andrew Chesterman. The Map - A Beginner's Guide to Doing Research in Translation Studies, St. Jerome, 2002.

Wizards of the Coast. M13 Basic Rulebook, 2012, http://media.wizards.com/images/magic/resources/rules/EN_MTGM13_Rulebook.pdf.

Accessed on: 02 Mar. 2020.

Wizards of the Coast. Gatherer - The Magic Card Database, www.gatherer.wizards.com. Accessed on: 02 Mar. 2020.

\footnotetext{
*MA study supervised by Professor Lincoln Fernandes (PPGI/UFSC, 2014).

${ }^{1}$ In fantasy games the word "races" is used instead of "ethnicity" because game races are usually mythological (e.g., angels, demons, sphinxes, dragons, hydras).

${ }^{2}$ Cf. Coletti.

${ }^{3}$ Cf. Vidal and Elias; Vidal (A experiência).

${ }^{4}$ Until the end of this MA study in 2014, and to the best of the author's knowledge.

${ }^{5}$ Goblins are part of the mythos in several European civilizations, such as the Celtics. They are often confused with other mythological creatures from European folklore, such as trolls, elves, and dwarves (see Bulfinch).

${ }^{6}$ According to personal communication with Brazilian certifier judge (DCI Level 2) Henrique Amigo.

${ }^{7}$ Available at www.copa-trad.ufsc.br.
} 


\footnotetext{
${ }^{8}$ The notion of segment used for this study is any string of text separated between two final stops. As for the card textual spoiler used later, the full text of each card was considered in its entirety for alignment.

${ }^{9}$ Flying did not present reminder text in Magic 2013; source of reminder text in Wizard of the Coast (Gatherer).

${ }^{10}$ In Planeshift, a set released in 2001.
}

\section{BIOGRAPHICAL NOTE}

Meggie Rosar FORNAZARI - Ph.D. (2018) and MA (2014) in English Linguistic and Literary Studies (2018), Universidade Federal de Santa Catarina. Licensed teacher in English (2012) from the same institutions. Autonomous Researcher. Florianópolis, Santa Catarina, Brazil.

ORCID: https://orcid.org/0000-0001-7062-2620

Currículo Lattes: http://lattes.cnpq.br/5433376826611157

E-mail: meggierf@gmail.com 